\title{
Hemocyanin as an apolipoprotein in the hemolymph of the cephalopod Octopus tehuelchus
}

\author{
Horacio Heras and Ricardo Pollero \\ Instituto de Investigaciones Bioquímicas de La Plata, UNLP-CONICET, Facultad de Ciencias Médicas, La Plata (Argentina)
}

(Received 16 July 1991)

(Revised manuscript received 9 January 1992)

Key words: Hemocyanin; Octopus lipoprotein; Lipid transport

\begin{abstract}
The three lipoproteins (LP) already recognized in octopus hemolymph (LP-I, LP-II and LP-III) were isolated by two-step density gradient ultracentrifugation from Octopus tehuelchus plasma. The protein moieties were examined by SDS and native polyacrylamide gradient electrophoresis. The main apolipoproteins were isolated by high-pressure liquid chromatography, hydrolyzed and their amino acid compositions were determined. All the lipoproteins share a protein unit of molecular weight 340000 that contains copper and covalently bound carbohydrates. On this basis, it was identified as the hemocyanin monomer; results from isoelectrofocusing in a $\mathrm{pH}$ gradient, amino acid composition and spectrophotometric behaviour corroborated this identification. The plasma fraction LP-III which is the carrier of half the hemolymphatic lipids, presents the simplest composition with hemocyanin as its unique apolipoprotein. LP-I and LP-II that transport most of circulating cholesterol and phospholipids, have hemocyanin as their predominant apolipoprotein and lesser amounts of polypeptides with minor molecular weights. Results suggest that $O$. tehuelchus lipoproteins have a fundamental protein structure constituted of hemocyanin, alone or associated to other polypeptidic chains. Probably, these polypeptides would modify the affinity of hemocyanin for certain lipids, giving origin to lipoproteins of different characteristics.
\end{abstract}

\section{Introduction}

The available information on the lipid transport system in molluscs is scanty. It is mostly referred to bivalves, and recently to cephalopods, too. Although it has been proved that bivalve hemocytes are engaged in triacylglycerol and cholesterol transport [1,2], most lipids are transported via plasma lipoproteins. In this sense, we have already reported that ingested lipids as well as those in the interorgan circulation are transported in plasma by means of three water-soluble lipoproteins $[3,4]$.

Blood lipid composition and the mechanism of lipid transport in cephalopods have only been studied in octopod hemolymph $[5,6]$. In hemolymph plasma from Oclopus tehuelchus, three lipoproteins were detected by using radiolabelled lipids. They were isolated and their lipid moiety compositions and densities characterized. The lipoproteins, LP-I, LP-II and LP-III have

Correspondence: R. Pollero, Instituto de Investigaciones Bioquímicas de La Plata, UNLP-CONICET, Facultad de Ciencias Médicas, 60 y 120, 1900-La Plata, Argentina. low, high and very high density, respectively. It was also proved that most cholesterol and phospholipids are transported by LP-I and LP-II, while free fatty acids, hydrocarbons, esterified sterols and minor amounts of triacylglycerols and phospholipids, circulate associated with LP-III.

We have also suggested the possibility that plasma hemocyanin, in addition to its well-known physiological role as oxygen carrier, would play some function in the lipid transport. In order to shed some light on this function of hemocyanin, in the present study, we isolated the three lipoproteins from Octopus tehuelchus plasma and investigated their apolipoprotein characteristics.

\section{Materials and Methods}

\section{Animals}

Specimens of Octopus tehuelchus were collected by scuba diving in shallow sand-bottom waters and maintained in aquaria for $24 \mathrm{~h}$ before the experiments were performed. In order to avoid the stress caused by transport to our inland laboratory, blood from the octopuses was obtained in situ by cardiac puncture. The blood was centrifuged at $2000 \times g$ for $15 \mathrm{~min}$ to 
separate hemocytes and plasma. Plasma samples were kept at $4^{\circ} \mathrm{C}$ and taken to the laboratory for analysis.

\section{Isolation of plasma lipoproteins}

Plasma from six to eight animals was carefully layered over a $\mathrm{NaBr}$ solution $1.30 \mathrm{~g} / \mathrm{ml}$ and centrifuged at $178000 \times \mathrm{g}$ for $20 \mathrm{~h}$ at $10^{\circ} \mathrm{C}$ [7] in a Beckman L8M ultracentrifuge. Saline solutions of densities equal to the plasma samples were run simultaneously as blanks. The tube contents were fractionated from the top and 19 fractions of $200 \mu \mathrm{l}$ each were obtained from both control and sample. Two fractions of densities 1.15$1.19 \mathrm{~g} / \mathrm{ml}$ and $<1.11 \mathrm{~g} / \mathrm{ml}$ were separated from the first centrifugation and were recentrifuged in $\mathrm{NaBr}$ solution of $1.19 \mathrm{~g} / \mathrm{ml}$ and $1.12 \mathrm{~g} / \mathrm{ml}$ densities, respectively.

Total proteins in each fraction were measured by the procedure of Lowry et al. [8]. Density was determined in a Bausch and Lomb refractometer.

Three fractions of densities $1.05-1.08,1.13-1.16$ and $1.22-1.27 \mathrm{~g} / \mathrm{ml}$, previously identified as LP-I, LP-II and LP-III, respcctively, were isolated and analyzed separately.

\section{Electrophoresis}

The fractions were pooled and extensively dialyzed against $62.5 \mathrm{mM}$ Tris- $\mathrm{HCl}$ buffer ( $\mathrm{pH} 6.8), 0.01 \% \mathrm{NaN}_{3}$, $\mathrm{CaCl}_{2} 10 \mathrm{mM}, 50 \mathrm{mM} \mathrm{MgCl} 2 \cdot 5 \mathrm{H}_{2} \mathrm{O}$ when they should be analyzed by native electrophoresis, and against the same buffer but without cations for the dissociating electrophoresis. In all the cases, temperature was kept at $4^{\circ} \mathrm{C}$.

Native polyacrylamide gradient gel electrophoresis (PAGE) was performed on $4-20 \%$ acrylamide gel slabs, overlayered with $3.75 \%$ stacking gels. The resolving gel buffer was $0.375 \mathrm{M}$ Tris- $\mathrm{HCl}(\mathrm{pH} \mathrm{8.8)}$ and the stacking gel buffer was $0.125 \mathrm{M}$ Tris- $\mathrm{HCl}(\mathrm{pH} \mathrm{6.8)}$ ). The electrode buffer contained Tris-glycine (0.021 M Tris, 0.192 $\mathrm{M}$ glycine) ( $\mathrm{pH}$ 8.3). Sodium dodecyl suphate-polyacrylamide gradient gel electrophoresis (SDS-PAGE) was performed following Laemmli procedure [9] using a $4-20 \%$ acrylamide gradient.

Proteins were visualized by staining with Coomassie brilliant blue, followed by destaining of the gel background.

Molecular weight standards (Pharmacia) were run in parallel lanes. Calibration markers included thyroglobulin, ferritin, catalase, lactate dehydrogenase and bovine albumin. A standard curve designed from their relative migration and known molecular weights was used to estimate the molecular weight of the apolipoproteins.

\section{Purification of apolipoproteins and amino acid analysis}

LP-III and LP-II apolipoproteins were analyzed by reverse-phase high-pressure liquid chromatography on an Aquapore RP-300 $\mathrm{C}_{4}$ column (Brownlee labs) using a linear gradient of water plus $0.1 \%$ trifluoroacetic acid (TFA) (solvent A) and isopropanol/water $(70: 30, v / v)$ plus $0.1 \%$ TFA (solvent B). The chromatograph employed was an IASCO apparatus coupled to a IASCOUVIDEC-1000-III detector. Proteins were detected at $220 \mathrm{~nm}$.

The amino acid composition of apoLP-III samples was determined in a Beckman $119 \mathrm{CL}$ amino acid analyzer. Duplicate samples were hydrolyzed in $6 \mathrm{M}$ $\mathrm{HCl}$ at $110^{\circ} \mathrm{C}$ in vacuo for $24 \mathrm{~h}$.

\section{Carbohydrate and copper detection}

The presence of covalently bound carbohydrate in lipoproteins and apolipoproteins was determined by periodate-Schiff on SDS-PAGE following the technique of Zacharius et al. [10].

Copper was detected in the PAGE gels following the procedure of Bruynick et al. [11]. The gels were immersed in a solution of $16 \mathrm{mM}$ ascorbic acid in acetic acid, containing $0.28 \mathrm{mM}$ bichinoleine for $3 \mathrm{~min}$. The presence of copper was observed under UV light at $254 \mathrm{~nm}$. Afterwards, proteins in the gels were stained with Coomassie blue.

\section{Isoelectric focusing}

Acrylamide gels $(7 \%)$ containing $2 \%$ of ampholytes (LKB-Pharmacia) $\mathrm{pH} \mathrm{4-6,} \mathrm{were} \mathrm{prefocused} \mathrm{with} \mathrm{suc-}$ cessive voltage increasing from 200 to $400 \mathrm{~V}$. L.P-III samples were diluted in $12 \%$ ampholytes, $20 \%$ glycerol buffer, 10 a final concentration of $3 \%$ ampholytes, $5 \%$ glycerol. Anodic and catodic solutions were $\mathrm{PO}_{4} \mathrm{H}_{3} 6.6$ $\mathrm{mM}$ and $\mathrm{NaOH} 10 \mathrm{mM}$, respectively.

Isoelectro-focusing was carried out at $400 \mathrm{~V}$ for 22 h. The $\mathrm{pH}$ was determined in a lane with no sample, by measuring pH every $5 \mathrm{~mm}$ in slices cut from the gel. A standard curve was drawn upon those values obtained from the distances between the cathode and that $\mathrm{pH}$ previously determined. Lanes containing samples were fixed and rinsed in order to eliminate ampholytes, and stained for focused bands detection with Coomassie blue. The isoelectric point $(\mathrm{p} /)$ was determined by measuring the distance from cathode, corrected according to original length of the gel, and the resulting distance was compared with the $\mathrm{pH}$ curve.

\section{Spectrophotometric measurements}

The absorbance values at 340 and $280 \mathrm{~nm}$ were measured before and after sample treatment with $\mathrm{KCN}$. To a LP-III solution (2 $\mathrm{mg}$ protein $/ \mathrm{ml}$ ), increasing quantities of $0.2 \mathrm{M} \mathrm{KCN}$ solution were added and the absorbances at both wavelengths were recorded with a Carl Zeiss spectrophotometer, using quartz $1 \mathrm{~cm}$ lightpath cells. 
Incubations with radioactive tracers

Liposomes containing $\left[4{ }^{14} \mathrm{C}\right]$ cholesterol $(55 \mu \mathrm{Ci}$. $\mu \mathrm{mol}^{-1}$, purchased from Amersham) and non-labelled phosphatidylcholine were administered to the octopuses to label plasma lipoproteins. Each animal was injected with $5 \mu \mathrm{Ci}$ of the radioactive lipid and maintained in the aquarium for $4 \mathrm{~h}$. After the incubations, hemolymph was obtained, centrifuged to separate hemocytes and labelled plasma was used to isolate lipoproteins.

\section{Results}

\section{Isolation of lipoproteins}

Lipoproteins were isolated and purified from hemolymph plasma of $O$. tehuelchus by ultracentrifugations in density gradients in accordance with previous work [6]. Fractions were separated on the basis of their densities after centrifugation on $\mathrm{NaBr} 1.30 \mathrm{~g} / \mathrm{ml}$, pooled and recentrifuged on $\mathrm{NaBr}$ solutions of minor densities. Fractions corresponding to LP-I, LP-II and LP-III were separated from the resulting density gradients and proteins were measured. From the total proteins of $O$. tehuelchus plasma, ranging between 74 and $79 \mathrm{mg} / \mathrm{ml}$, about $99 \%$ corresponded to LP-III, a highly pigmented blue fraction.

\section{Characterization of apoLP-III}

The native PAGE of this lipoprotein showed two protein bands with apparent molecular weights of 340000 and 675000 , respectively (Fig. 1). Although runs were done for different times until the proteins reached the limiting pore size of the gradient gel, limiting the elctrophoretic migration of the proteins to relative size only, they might give erroneous molecular

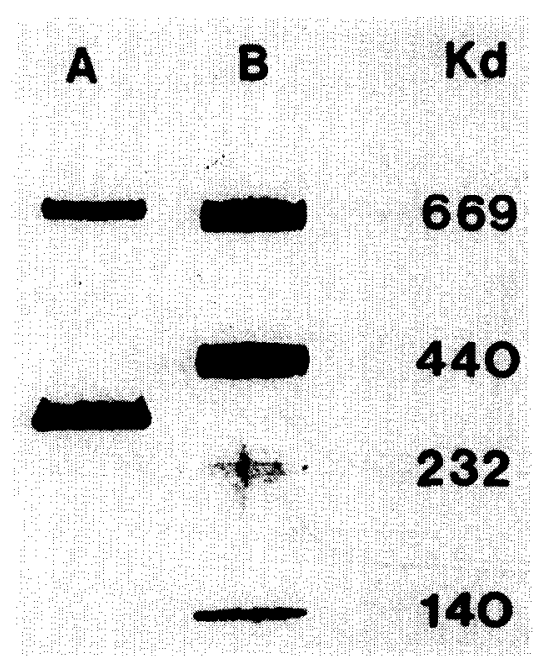

Fig. 1. Polyacrylamide gel electrophoresis of native lipoprotein I.P-III, isolated from $O$. tehuelchus plasma. Lipoprotein sample (A); molecular weight standards (B). The samples were applied on a $4-20 \%$ gradient slab containing a $3.75 \%$ acrylamide stacking gel.

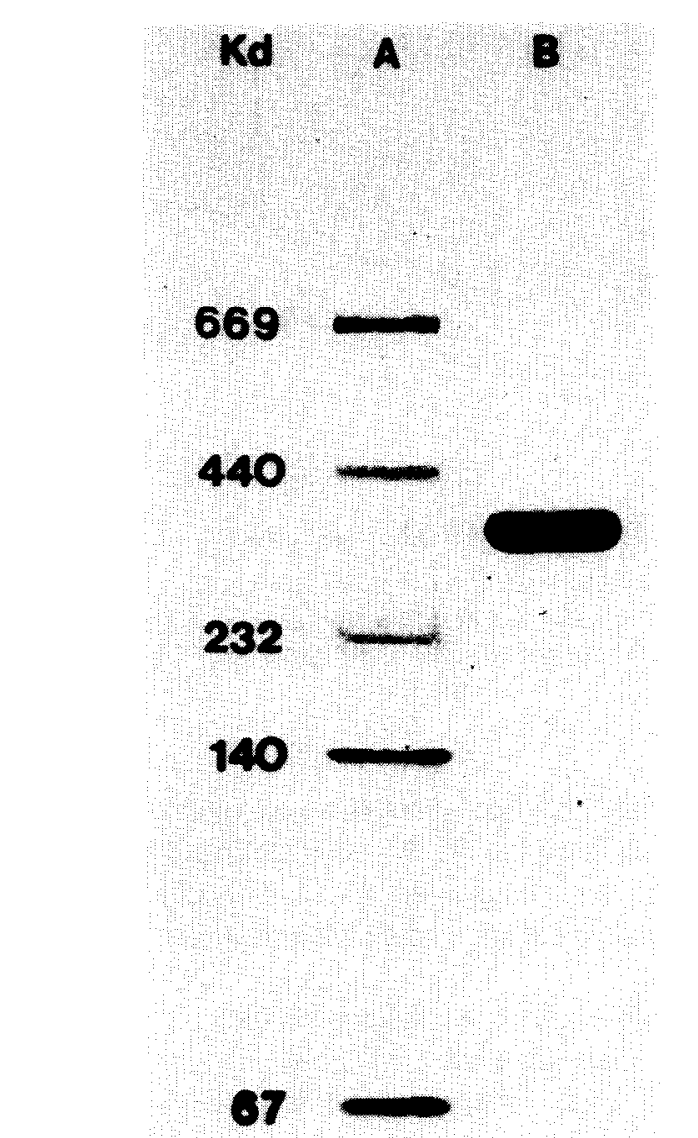

Fig. 2. SDS-polyacrylamide gradient gel electrophoresis of apolipoprotein LP-III isolated from $O$. tehuelchus plasma. Molecular weight standards (A) and lipoprotein sample (B).

weight estimations. So, the obtained values could only be considered approximately. When electrophoresis was done on the same sample in dissociating conditions (SDS-PAGE), only the protein band with a molecular weight of 340000 appeared (Fig. 2). These results were not altered by treating the samples with $\beta$-mercaptoethanol followed by SDS-PAGE.

Covalently bound carbohydrates were evidenced in this unique protein band of LP-III by positive periodate-Schiff staining of the SDS-PAGE slab. The presence of copper in this protein was detected by using bichinoline reactive, which gave a positive reaction. in the PAGE gels.

ApoLP-III was then separated by reverse-phase HPLC. The elution profile shown in Fig. 3 indicates that this lipoprotein elutes as a single peak. The amino acid composition of the isolated apoLP-III was studied and summarized in Table 1 . The main features of the amino acid composition are the high content of aspartate, glutamate, leucine and phenylalanine.

In order to add further information related to the characterization of apoLP-III, its isoelectric point was determined by electrofocusing and was estimated to be 5.1. In addition, it was determined for its spectrophoto- 


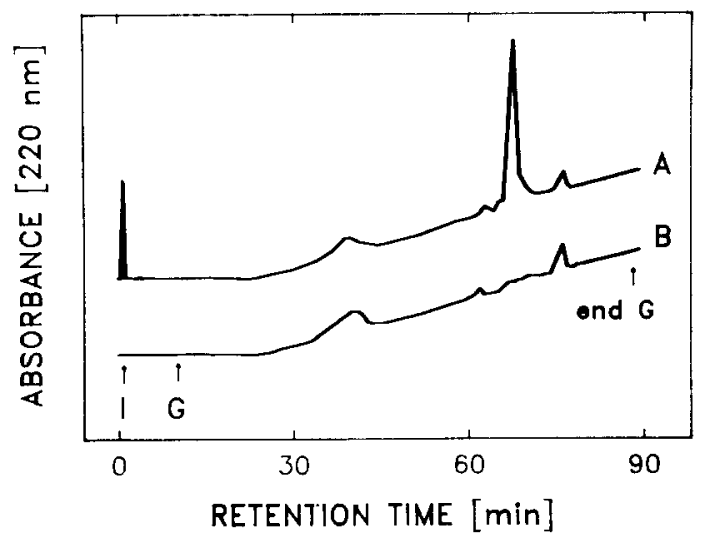

Fig. 3. Elution profile from reverse-phase HPLC of plasma fraction LP-III. Chromatography was performed on an Aquapore RP-300 C4 column. (A) apoLP-III sample. (B) blank of solvents. I, injection: G. gradient.

metric behaviour. When increasing quantities of $\mathrm{KCN}$ were added to the protein, the $340 / 280 \mathrm{~nm}$ absorbance relationships were registered from an initial value of 0.16 to the disappearance of the band at $340 \mathrm{~nm}$.

\section{Characterization of LP-II apolipoproteins}

LP-II, isolated from density gradient ultracentrifugations, was firstly characterized with respect to its protein moiety, by electrophoresis under native and denaturating conditions. The native electropherogram illustrated in Fig. 4 indicates that this fraction contains

\section{TABLE 1}

Amino acid composition of apo-LP-III and the main apo-LP-II from O. tehuelchus plasma.

Results are the mean of two 24 h-hydrolyzates of HPLC isolated proteins.

\begin{tabular}{|c|c|c|c|c|}
\hline \multirow[t]{2}{*}{ Amino acid } & \multicolumn{2}{|l|}{ ApoLP-III } & \multicolumn{2}{|l|}{ Main apoLP-II } \\
\hline & residues/mol & $\mathrm{mol} \%$ & residues/mol & $\operatorname{mol} \%$ \\
\hline Aspartate ${ }^{*}$ & 350 & 9.94 & 336 & 11.98 \\
\hline Threonine & 161 & 4.82 & 140 & 4.50 \\
\hline Serine & 165 & 4.40 & 182 & 5.16 \\
\hline Glutamate * & 305 & 12.07 & 336 & 13.29 \\
\hline Glycine & 171 & 3.07 & 175 & 3.54 \\
\hline Alanine & 196 & 4.11 & 189 & 4.54 \\
\hline Valine & 185 & 5.6 .5 & 203 & 6.41 \\
\hline Methionine & 66 & 2.02 & $\mathrm{t}$ & - \\
\hline Isoleucine & 150 & 4.98 & 133 & 4.70 \\
\hline Leucine & 272 & 9.05 & 224 & 7.92 \\
\hline Tyrosine & 135 & 6.50 & 119 & 5.81 \\
\hline Phenylalanine & 200 & 9.32 & 217 & 9.67 \\
\hline Hystidine & 165 & 6.65 & 147 & 6.16 \\
\hline Lysine & 180 & 6.91 & 182 & 7.17 \\
\hline Arginine & 137 & 6.61 & 133 & 6.25 \\
\hline Proline & 140 & 3.83 & 154 & 4.78 \\
\hline Tryptophan & nd & - & nd & - \\
\hline Cysteine & nd & .- & nd & - \\
\hline
\end{tabular}

* Includes acid + amide. nd: not determined. t: traces.

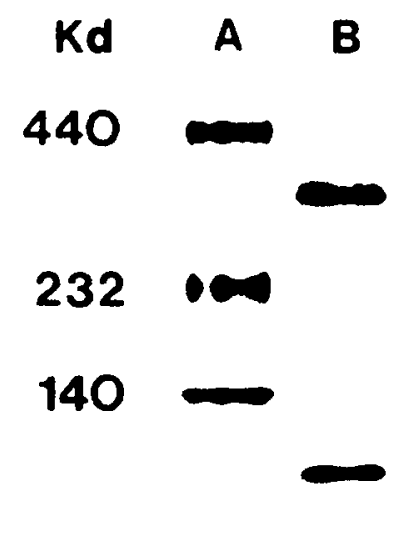

67

Fig. 4. Polycrylamide gradient gel electrophoresis of native lipoprotein LP II isolated from $O$. tchuclehus plasma after two-step density gradient ultracentrifugation. Molecular weight standards (A) and lipoprotein sample (B).

three different apolipoproteins. Their molecular weights were estimated to be about 340000,230000 and 129000 .

Electrophoresis under denaturating conditions (SDS-PAGE) revealed that the 340000 and 230000 proteins remained unaltered, while the 129000 protein disappeared, yielding a protein of approximately 21000 .

Fig. 5 shows the elution profile of LP-II apolipoproteins, being separated by reverse-phase HPLC. In this case, a protein heterogeneity higher than that found in the SDS-PAGE, was evidenced. Also noteworthy was a conspicuous peak number 4 in the figure) with a retention time coincident to the apoLP-III. This main apolipoprotein of LP-II, purified by preparative HPLC, was subjected to amino acid analysis. The

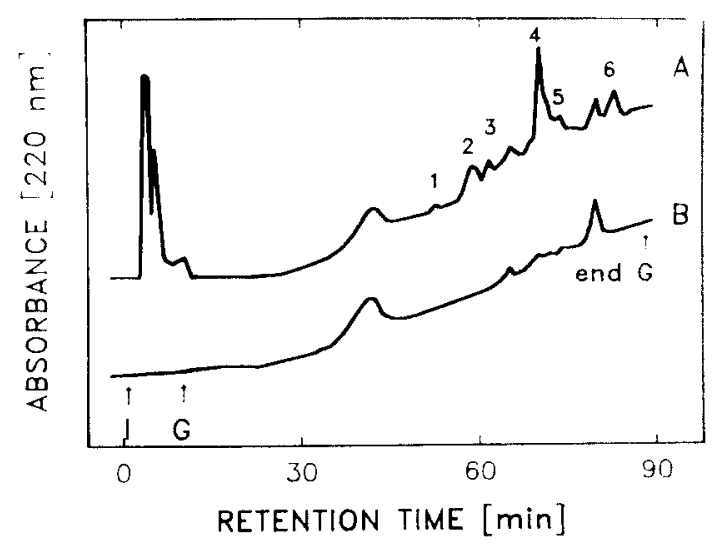

Fig. 5. Elution profile from reverse-phase HPLC of plasma fraction LP-II. (A) apoLP-II. (B) blank of solvents. 
results showed an amino acid composition similar to the one in the apoLP-III (Table I).

\section{LP-I apolipoproteins}

LP-I was analyzed by electrophoresis under native as well as in denaturating conditions. In both cases the presence of the protein band with a molecular weight of 340000 was evidenced. The low concentration of LP-I in plasma did not allow a thorough apolipoprotein characterization.

Although the 340000 apolipoprotein was the unique protein band visualized on the gels by staining methods, it was possible to detect a second apolipoprotein by labelling the LP-I lipid moiety with radioactive cholesterol. When labelled LP-I was analyzed by native electrophoresis, gel was fractionated and radioactivity of each fraction was measured, the distribution of radioactivity in the gel showed that labelled cholesterol was associated approximately $44 \%$ to the 340000 apolipoprotein, and approximately $56 \%$ to a non-stained apolipoprotein of 129000 .

\section{Discussion}

From the electrophoretic analysis of LP-III, it is noted that this lipoprotein, under non-dissociating conditions, shows two protein bands where one of them duplicates approximately the molecular weight of the other. Meanwhile, under denaturating conditions, only the protein of highest mobility remains. The invariability in the electrophoretic behaviour of the latter band, after treating it with a dissociating reagent of protein chains, indicates that this subunit is composed of only one polypeptide. These facts and some others, such as the detection of copper and carbohydrates in those proteins, or the blue colour of the purified LP-III fraction, suggested that both bands corresponded to the dimer and monomer of hemocyanin, respectively. This protein, common in molluscs and arthropods [12], was characterized at an early date as a cuproglycoprotein. It fulfils the function of respiratory pigment [13], and is by far the main plasma protein in octopods. The presence of the subunits of hemocyanin in the native electrophoresis may be due to a dissociation of an oligomer, since the hemocyanins of cephalopods are found to have structures consisting of ten subunits subjected to dissociation $[14,15]$. Such a loss of the native conformation of this molecule could be the consequence of changes in the $\mathrm{pH}$, the divalent cation concentration when processing the samples or to the $\mathrm{NaBr}$ used in the centrifugation procedure. The effect of cations on the association-dissociation equilibria has been studied in depth in octopi and other mollusc hemocyanins [16-18]. The molecular weight estimated for the protein in LP-III is close to one-tenth of those determined by light scattering for hemocyanins of three species of octopi [17], and the value estimated for its isoelectric point is also in agreement with those already reported for the hemocyanin monomers in other octopods [19]. The removal of copper by $\mathrm{KCN}$ treatment resulting in the disappearance of the characteristic copper-oxygen band in the hemocyanin absorption spectrum, reinforced this identification.

Even though all the characteristics mentioned above could be considered valid for the conclusion that this apolipoprotein is identical to hemocyanin, we thought it appropriate to analyze further the amino acid composition of this protein after isolation and purification by HPLC. A marked similarity was found between the amino acid composition of this protein and the one reported for hemocyanins of other octopods [20]. High pressure liquid chromatography was also utilized in order to explore the possible existence of some other proteins associated to hemocyanin, resulting in the formation of the LP-III fraction. The results obtained clearly show that this very high density lipoprotein contains only one protein component. Summing up all the evidence, it may be concluded that hemocyanin is the only apolipoprotein present in the LP-III fraction of $O$. tehuelchus plasma.

It has been reported that hemocyanin of the crab Carcinus maenas contains a small percentage of associated phospholipids. They would play only a stabilizing role within the protein structure [21], since the hemocyanin of crustacean is not involved in the lipid transport [22]. Though LP-III has a low lipid/protein ratio, it is of the greatest quantitative importance among $O$. tehuelchus plasma fractions, since it is in charge of transporting half of the hemolymphatic lipids [6]. Undoubtedly, results of these previous studies on lipid composition and the present ones on the apolipoprotein composition are not enough to fully describe the LP-III structure. However, the fact that LP-III contains a high proportion of very low polarity compounds such as hydrocarbons and esterified sterols, suggests the existence of a true lipoprotein. It may be speculated that these compounds would be arranged like a core surrounded by the most polar lipids and hemocyanin.

The plasma fraction LP-II also shows a protein band with electrophoretic characteristics similar to those of hemocyanin, and with the same chromatographic behaviour. Although the plasma concentration of this lipoprotein is low, it was sufficient to allow the isolation and purification of its main apolipoprotein and to study its constituent amino acids. Differences between the amino acid composition of the main apoLP-II and that corresponding to the apoLP-III were found to be small to fall into the error of the technique employed. The low concentration of LP-I made it rather difficult to outspread the apolipoprotein characterization, mainly with respect to its purification by HPLC, amino 
acid composition analysis and $\mathrm{p} I$ determination. However, it was possible to detect a protein band with hemocyanin characteristics also in this lipoprotein. Consequently, we may conclude that the hemocyanin monomer is found as an apolipoprotein in the three plasma lipoproteins of $O$. tehuelchus.

In contrast to LP-III, plasma fractions LP-I and LP-II contain not only hemocyanin but also lesser amounts of other proteins. These ones have been partially characterized, and for this reason, it may be too speculative to report on their function in the transport of lipids. Nevertheless, it must be taken into account that most of circulating phospholipids, free cholesterol and triacylglycerol have been recognized and quantified in LP-I as well as in LP-II [6]. Thus, it may be suggested that proteins associated to hemocyanin could play as important functions as apolipoprotein. As regards LP-I, our results are clear enough to demonstrate that cholesterol is carried associated to hemocyanin as well as to another protein of smaller molecular weight. These are the only protein components detected in LP-I and both of them are also present in LP-II with some other proteins. Summing up, it may be said that lipoproteins of $O$. tehuelchus have a fundamental protein structure constituting hemocyanin, alone or associated to other polypeptidic chains. In insects such as Leptoglosus zonatus and Manduca sexta, it was detected that a small amount of an apolipoprotein which associated to a high density lipoprotein, increases its capacity of mobilizing lipids, giving rise to a low density lipoprotein [23]. A similar association could be found in Triatoma infestans [24]. Perhaps, in our case, the apolipoproteins associated to hemocyanin play a similar role. Therefore, they would increase the affinity of hemocyanin for certain lipids, giving origin to LP-I and LP-II. Further investigation dealing with these proteins, either isolated and purified, is needed to achieve the final elucidation.

\section{Acknowledgements}

This research has been supported by a grant from CONICET, Argentina. The authors are indebted to the staff of Laboratorio de Recursos Bentónicos y Cultivos Marinos, Instituto de Biología Marina y Pes- quera "Alte. Storni", Argentina, for their help. R.P. is a member of the Carrera del Investigador Cientifico, CIC Pcia. de Buenas Aires, Argentina.

\section{References}

1 Allen, W.V. and Conley, H (1982) Comp. Biochem. Physiol. 71 B. $201-207$.

2 Pollero, R.J., Huca, G.A. and Brenner, R.R. $(1985)$ Comp. Biochem. Physiol. 82A, 339-343.

3 Pollero, R.J. (1987) Comp. Biochem. Physiol. 88A, 577 -580.

1 Pollero, R.J. and Heras, H. (1989) Comp. Biochem. Physiol. $13 \mathrm{~A}$. $673-676$.

5 Heras, H. and Pollero, R.I. (1989) Comp. Biochem. Physiol. 91A. $571-575$.

6 Heras, H. and Pollero. RJ. (1990) J. Exp. Mar. Biol. Ecol. I H) $29-38$

7 Lindgren, F.T. (1975) in Analysis of Lipids and Lipoproteins (Perkins, E.G., ed.). pp. 204-224, Am. Oil Chem. Soc. Champaign.

8 Lowry, O.H., Rosebrough, N.I., Farr, A.I. and Randall, R. (1951) J. Biol. Chem. 193, 265-275.

9 Laemmli, U.K. (1970) Nature $227,680-685$.

10) 7achrius, R.M., 7ell. T.F.. Morrion. I.H and Wooldhock 1 I (1969) Anal. Biochem. 30, $148 \cdots 152$.

I1 Bruynick, W.J., Gutteride, S. and Mason. H.S. (1978) Anal. Biochem. 89. 174-177

12 Ghiretti, F. and Ghiretti-Magaldi, A. (1972) in Chemical Zoology (Florkin, M. and Scheer, B.T.. eds.) Vol. VII Mollusci, pp. 201-217. Academic Press, New York.

13 Miller, K.l. and Van Holde, K.E. (1986) in Invertebrate Oxygen Carriers (Int. Conf.) (Lindzen, B., ed.), pp. 417, Springer, Berlin.

14 Van Holde, K.E. and Miller, K.I. (1982) Q. Rev. Biophys. 15. $1-29$.

15 Herskovits, T.T. (1988) Comp. Biochem. Physiol. 91B, 579-611.

16 Van Holde, K.E. and Miller, K.I. (1986) in Invertebrate Oxygen Cariers (Int Conf.) (Lindzen, B. ed.), pp. 245, Springer, Berlin.

17 Herskovits, T.T. and Villanueva. G.B. (1986) Biochemisiry 25. $931 \ldots 939$.

18 Herskovits, T.T.. Cousins, (..J. and Hamilton. M.C. (1991) Biochim. Biophys. Acta 1076, $71-78$.

19 Van Holde, K.E. (1967) Biochemistry 6, 93-98.

20 Ghiretti, F. (1966) in Physiology of Mollusca (Wilbur, K.M. and Yonge. C.M. eds.). Vol. II, pp. 233-240, Academic Press, New York.

21 Zatta, P. (1981) Comp. Biobcem. Physiol. 60, 731--735.

22 Beenakers. A.D.T., Van Der Horst, D.J. and Van Marrewijk. W.J.A. (1985) Prog. Lipid Res. 24, $19-67$.

23 Surholt. B.. Schultz, K.T., Goldberg, J., Van Der Horst. D.J. and Beenakers, A.D.T. (1988) Insed Biochem. 18, $117 \ldots 126$.

24 Fichera, L.E. and Brenner. R.R. (1985) Acta Physiol. Pharmacol. latinoam. 35, 319-325. 